Wright State University

CORE Scholar

\title{
Librarians in the Midst: Improving Student Research Through Collaborative Instruction
}

\author{
Mandy Shannon \\ Wright State University - Main Campus, mandy.shannon@wright.edu \\ Vaughn Shannon \\ Wright State University - Main Campus, vaughn.shannon@wright.edu
}

Follow this and additional works at: https://corescholar.libraries.wright.edu/ul_pub

Part of the Information Literacy Commons, and the Scholarship of Teaching and Learning Commons

\author{
Repository Citation \\ Shannon, M., \& Shannon, V. (2016). Librarians in the Midst: Improving Student Research Through \\ Collaborative Instruction. Journal of Political Science Education. \\ https://corescholar.libraries.wright.edu/ul_pub/172
}

This Article is brought to you for free and open access by the University Libraries at CORE Scholar. It has been accepted for inclusion in University Libraries' Staff Publications by an authorized administrator of CORE Scholar. For more information, please contact library-corescholar@wright.edu. 


\title{
Librarians in the Midst:
}

\section{Improving Student Research Through Collaborative Instruction}

\author{
Amanda Shannon, MA, MSLS \\ Coordinator of Library Instruction \& Assessment \\ Wright State University \\ 328 Dunbar Library \\ Dayton, $\mathrm{OH}$ 45435-0001 \\ mandy.shannon@wright.edu \\ 937.775.3149 \\ Vaughn Shannon, PhD \\ Associate Professor of Political Science \\ Wright State University \\ 314 Millett Hall \\ Dayton, $\mathrm{OH}$ 45435-0001 \\ vaughn.shannon@wright.edu \\ 937-775-5767
}

\begin{abstract}
A previous version of this paper was presented at the annual meeting of the American Political Science Association, September 5, 2015, in San Francisco, CA. We benefited from a fruitful discussion there, and especially thank Arthur Sanders for his time and comments. We also thank Jeff Bernstein and Mary Lou Baker Jones, both of whom have made this a stronger and more readable paper. Thanks to Graduate Assistant Rahimullah Akrami for his research and anonymization efforts.
\end{abstract}




\begin{abstract}
We test whether and how well the presence of an embedded librarian improves the quality of student research. Students in introductory-level courses tend to have very low levels of research skills and experience. Though faculty are frustrated by this lack of skills, both students and faculty tend to have only a peripheral knowledge of the role librarians can play in helping develop their research skills. Studies suggest that embedding librarians into course instruction is the preferred method for improving students' research skills, yet the political science teaching and learning literature rarely addresses this issue, or focus on single class experiences, measuring change in student knowledge and skills from the beginning to the end of a semester. We compare two International Politics courses taught in consecutive fall semesters with different levels of librarian involvement in the class. We assess the changes in quality and use of information sources in the final research papers, both from a bibliographic perspective (looking at the number, quality, and variety of sources used) as well as an information use perspective (looking at the relevance of cited material in supporting arguments).
\end{abstract}

KEYWORDS: information literacy, embedded librarianship, collaborative instruction 
“Knowledge is useless if you don't know how to find it, if you don't even know where to begin to look." - Patrick Ness ${ }^{1}$

\section{Introduction}

At the end of any given academic term, it is not uncommon to witness frustration across a college campus. Students are overwhelmed by research assignments that they may view as unnecessarily difficult. Faculty are often disheartened by the work submitted by many students. This mutual frustration can be explained, in part, by competing expectations about the research process. Students new to college-level research express two sets of responses to research assignments: they find it "exciting" to be able to explore new topics, but find the assignments "scary" or "overwhelming" (Head, 2013). Meanwhile, faculty often expect that their students will have had previous training in how to conduct research. The reality is that very few students come to college having had to write a research paper at all, let alone one that is at the level expected for most college courses.

Students in introductory-level courses tend to have very low levels of research skills and experience (e.g., Barria, Mueller, and Wandling 2013; Thornton 2010; Head 2013). However students typically don't view themselves as having low levels of skill or ability when it comes to doing research. Comparisons of faculty and student perceptions of research ability are striking. For example, a Credo survey (2015) found that 54\% of students identified as either "confident" or "very confident" in their abilities to evaluate the authority of an information sources; in the

\footnotetext{
${ }^{1}$ From Patrick Ness's acceptance speech for the 2011 Carnegie Medal, as quoted in The Guardian news coverage of the event.
} 
same survey only $16 \%$ of faculty were confident in their students' abilities in this skill. Similar gaps exist in perceptions about students' ability to use scholarly sources and incorporating sources into a paper. Scholars of the stages of learning would likely be unsurprised, noting that novices in any field are seen as having unconscious incompetence (e.g., Evans 2007; McPherson 2005). That is, as students begin the research process, they don't know what they don't know. Student frustration comes, as well, by recognizing the problems they have in finding and evaluating information (Head 2008).

Part of the challenge comes from an expectation that students as "digital natives" (Prensky 2001) have the ability to navigate the digital environment to conduct research. However, familiarity with the online environment does not translate to research skills. According to a Pew Internet and American Life report on how teens conduct research in the digital world, “teachers and students alike report that for today's students, 'research' means 'Googling”" (Purcell et al. 2012, 3). While this is often perceived as lazy or lack of effort, it is frequently the result of a generation approaching research when there is simply too much information (Thornton 2010). Whether it is referred to as "information obesity" (Whitworth 2009), a "tsunami of global information" (Weeks 2011), or "information overload" (Johnson 2010), the glut of information available in the digital age can be particularly challenging for students approaching college-level research for the first time.

Among faculty, there is often a similar disjoint between expectations and experience. Frequently, faculty assume that students have already been taught many of the basic skills of information literacy, including identifying the scope of their information needs, distinguishing between popular and scholarly sources, and evaluating information (Jackson, MacMillan, and 
Sinotte 2014). Indeed, the skills that are perceived as most important by faculty are also those they expect that students will learn skills independently or in other classes (Jackson, MacMillan, and Sinotte 2014).

While students lack research skills, and faculty are frustrated by this lack of skills, both tend to have only a peripheral knowledge of the role librarians can play in helping develop their research skills. Even when a professor includes the librarian's contact information on a syllabus, student perceptions continue to be that librarians are available to help only with books (Lundstrom and Shrode 2013). This misperception hides the role that librarians can play in promoting information literacy in the classroom. Many of the problems with students' research papers, as reported by grading faculty, are problems that are addressed by information literacy instruction (Stevens and Campbell 2008). This study seeks to test the role of librarians embedded in the classroom to facilitate information literacy and produce quality research to the benefit of students and faculty alike. We test the impact of having a librarian embedded in the classroom on students' information literacy and the subsequent quality of their research.

\section{Information Literacy and Embedded Librarianship}

Information literacy is defined by the Association of College and Research Libraries as "a set of abilities requiring individuals to recognize when information is needed and have the ability to locate, evaluate, and use effectively the needed information" (ACRL). The concept of information literacy was originally introduced in 1974 by Paul Zurkowski at the National Program for Library and Information Services (National Commission on Library and 
Information Science, 1974). Notably, one of the earliest publications with a focus on enhancing information literacy through library instruction focused on the need for this in teaching state politics (Owens, 1976). Though the focus on information literacy was initially limited, by the late 1980s and early 1990s information literacy was a dominant focus of librarians. Indeed, Stephen Foster (1993) observed that the "[1]ibrary literature currently reverberates with a nearmissionary zeal with the cause of information literacy." Over the past two decades, the foundational ideas behind information literacy have become the predominant instructional focus of many, if not most, academic libraries (Tewell 2015), supplanting library instructional sessions that traditionally focused on tools-based approach ("just show them how to use the databases").

Traditional library instruction is often limited to one session with a librarian, known colloquially as a "one-shot." Multiple studies suggest that the effect of this instruction on student outcomes is limited, at best. Portmann and Roush (2004) found that one hour of library instruction increased the likelihood that students would use the library's services and resources, but did not influence the students' library skills. Conway (2015) and Howard, Nicholas, Hayes, and Appelt (2014) likewise found that students were more likely to use library resources after library instruction, but also found that the one-shot instruction did not increase either the quantity or diversity of sources cited. Soria, Fransen, and Nackerud (2013) found significant impacts on student GPA and retention for a number of library-related interactions, including database use, use of electronic journals, and use of computer workstations, but did not find a significant relationship between GPA or retention and library instruction. Academic librarians have given a great deal of focus on understanding how to either enhance effectiveness of the one-shot interaction or to address whether the assessment tools used are appropriate measures of the 
authentic outcomes. Walker and Pearce (2014), for example, examined the effect of greater engagement in the classroom through user-centered instruction. They found that, regardless of the delivery method, the one-shot is ineffective in "serving the information needs of students (p. 286)." Gauging the effectiveness of one-shots can be problematic, as well.

Other studies focus on assessing the effects of library instruction but assess affective responses or rely on student responses to questions about library skills (e.g., Choinski and Emanuel 2006) rather than authentic assessment of outcomes. Coulter, Clarke, and Scamman (2007) identify a reliance in the field on pre- and post-tests, anecdotal evidence, and affective surveys. In an attempt to move toward more authentic assessment, they compared the final course grades of students who received one-shot library instruction with students who received no library instruction and found no measurable difference in final course grade.

Addressing the constraints inherent in one-shot instruction sessions, there has been a move toward a more intensive presence in the classroom by librarians. While the form this takes can vary greatly in practice, the overarching idea of an increased presence of a librarian is collectively known as "embedded librarianship." Embedding librarians into course instruction is a growing field of research in the library literature, and many suggest that this is the preferred method for enhancing and improving students' research skills (e.g., Bundy 2004; Steven and Campbell 2007; Shumaker 2012). The political science teaching and learning literature, however, rarely addresses this issue. Moreover, studies that do investigate embedded librarians' impact tend to focus on single-class experiences, measuring change in student knowledge and skills from the beginning of a semester to the end of a semester, without a baseline measure where there is no library involvement (e.g., Gandhi 2004; Hearn 2005). 
There is also a tendency in these studies to measure student outcomes with pre- and posttests or affective self-evaluations of confidence in skills, rather than authentic assessments of student work (e.g., Edwards, Kumar, and Ochoa 2010). Generally, research on embedded librarianship tends to rely largely on descriptive case reports, while quantitative studies examining student outcomes are lacking (Schulte 2012). Recent work at Claremont Colleges Library addresses this challenge head-on, with a rubric-based analysis of different levels of librarian involvement in classes. Booth et al. (2015) examine the impact of both librarian instruction engagement level (measured by number of instruction sessions, development of course guides, etc.) and level of collaboration on syllabus and assignment design. They found that higher levels of librarian involvement correlated with higher student performance on written papers.

In addition to an increasing focus on the level of collaboration between faculty and librarians, there are calls to move away from "one-size-fits-all" models of information literacy instruction and towards instruction specific to the course content in classes (Stevens and Campbell 2008). While evidence suggests that library instruction ought to be integrated in course work rather than presented as separate from courses in the discipline, political science pedagogy literature has not included a heavy focus on information literacy (Williams and Evans 2008). In 2008, the Law and Political Science Section (LPSS) of the ACRL published "Political Science Research Competency Guidelines," based on the work of scholars of political science pedagogy (Ishiyama 2005; Ishiyama, Breuning, and Lopez 2006; Marfleet and Dille 2005; Wahlke 1991). This document argues for a structure to teaching research skills in the political science curriculum and offers a general guideline for collaboration between librarian and faculty, 
identifying their respective areas of expertise in teaching research skills (Norelli et al. 2008). While there was an uptick in the literature focusing on collaborations between librarians and political science faculty in the mid-2000s (e.g., Stephens and Campbell 2008; Marfleet and Dille 2005; Williams, Goodson, and Howard 2006; Thornton 2006, 2008), attention has seemingly moved away from this relationship and the importance of integrating information literacy in the political science classroom since the beginning of this decade. ${ }^{2}$ A notable exception in recent years is Gilbert, Knutson, and Gilbert's (2012) study of the effects of integrating library instruction in political science research methods classes. They found support for their hypothesis that students with more library instruction would have a better understanding of sources available for use and select higher quality sources. A more recent example of the interplay between information literacy and the political science classroom is in the inclusion of a chapter dedicated to information literacy in the recent Handbook on Teaching and Learning in Political Science and International Relations (Thornton 2015).

We contribute to the understanding of the effects of collaboration between librarians and political science faculty on discipline-specific learning outcomes. Our study adds to the body of literature that affirms the importance of collaboration between librarians and academic faculty, specifically within political science, to improve student learning outcomes.

\footnotetext{
${ }^{2}$ This interpretation is based on specific searches within political science pedagogy journals including $P S$ and Journal of Political Science Education, as well as a federated search on the terms: ("information literacy" or librar*) and "political science".
} 


\section{Research Design}

The research design employed for this study is quasi-experimental, in that we seek control and manipulation but lack complete power to randomly assign subjects to treatment groups. One of the authors, an American political scientist from the Midwest, committed to teaching an introductory class on International Politics fall semester of both 2013 and 2014. In essence, this controlled for instructor, time of year and instructor-related course content (same syllabus, assignments, lecture topics, and textbooks) to the extent possible.

The dependent variable in the study is the quality of student research, measured in several ways. The student research assignment we evaluated required students to analyze the position of a specific country on a current policy issue (e.g., Ebola outbreak, Syrian Civil War, etc.). Political science research requires a fairly sophisticated understanding of what types of information are available for different information needs. For this analytical assignment, a wellresearched paper would necessarily include several different information types: scholarly journal articles; news sources; and policy documents from international organizations and government sources. For students whose introduction to academic research is limited, this can not only be overwhelming, but also stretch beyond the bounds of their conceptions. They often don't know how to identify the different information needs implicit in this type of assignment, nor do they know where to go to find that information.

The independent variable, and the chief difference between the two classes, is the presence or absence of embedded, sustained librarian instruction. In 2013, the class had no visits from a librarian, and the librarian was not involved in syllabus construction or assignment evaluation. The librarian's name was included in the syllabus as a resource for research help, but 
no additional discussion of the ways the librarian could work with students was included. In 2014, the librarian was explicitly embedded in the class in the following ways. First, the librarian's information was in the syllabus next to the instructor's information, rather than in the body of the syllabus. Second, the faculty member and librarian collaborated on introducing the research assignment to students. Third, two full class sessions were dedicated to information literacy instruction. Fourth, the collaboration included the addition of a librarian-reviewed annotated bibliography midway through the semester to provide formative assessment for teaching, as well as to structure the research process more for students. Fifth, the librarian also visited the class in several informal visits, to provide worksheets focusing on the point of work the students were at and to provide an outlet for research-based questions from students.

In the first visit, the librarian focused on the importance of information in academic research, specifically on determining information needs and matching sources to the information need and evaluating sources found through general internet searches. Students were tasked with identifying the different types of information they would need to complete their assignments. The librarian led a discussion about different types of information provided by government sources, news reports, think tanks, and scholarly articles and what different types of questions each sources would address. The class visit included a discussion about the role of the various sources' potential bias and ways to contextualize that within the research paper.

In the second class visit, the librarian reiterated the importance and role of scholarly journal articles in an analytical writing assignment. Students had hands-on practice with using subscription databases after an overview of identifying appropriate databases for their research needs and a lesson on effective search strategies within the databases. Students were also given instructions for an annotated bibliography assignment that the librarian designed in collaboration 
with the faculty member for formative assessment. Students were required to submit annotated bibliographies of ten sources they had investigated several weeks before their final papers were due. This was a low-stakes assignment in which they were either given credit for completing it or not. The annotated bibliography assignment served two purposes. First, because students were encouraged to include both sources they thought would be useful for their final paper and those that had decided against using, the goal was to encourage critical evaluation of the relevance of sources to their research. Second, while the students weren't graded on the quality of sources, they did receive guidance on the direction their research was taking in the form of feedback from both the faculty member and librarian on the quality of sources and their relevance to their topic.

In addition to the two full-length class visits, the librarian also visited informally on several occasions: the first day of the semester for introductions and her availability to provide assistance in the research process; to return annotated bibliographies with feedback and worksheets on thinking about how to put the different pieces of information together for their papers (see Appendix B); and to check in on whether there were any questions or concerns about their research before the assignment deadline.

We assess the changes in quality and use of information sources in the final research papers, both from a bibliographic perspective (specifically, looking at the number, quality, and variety of sources used) as well as an information use perspective (specifically, looking at the quality of argumentation and relevance of cited material in supporting arguments). The dataset created for this project is based on research papers written by the students. The $\mathrm{N}$ for the papers is 66 (37 for 2013 and 29 for 2014). We concentrate on the quantity and quality of demonstrated research skills gleaned from a research paper assigned to both groups. 
Both authors conducted coding of the sixty-six papers, which were anonymized and assigned random numbers by a graduate research assistant. For each of the papers, we did a quantitative assessment of sources as well as a quantified assessment of information literacy in student writing. The source assessment involved two aspects. The first aspect was straightforward: we did a basic source count to see how many sources were used. Having put no mandatory minimum in the assignments, students could in theory have cited as few as one. Without prompting or required source minimums by the instructor or the assignments, we wanted to see if the number and quality of sources improved in the 2014 condition of an embedded librarian. We report a simple source count for each paper, sorted by the 2013 and 2014 conditions.

The second aspect of source assessment categorized the use of sources by type. Using a variety of sources implies both an awareness of and distinction between scholarly sources, general informational sources, and less legitimate sources such as non-expert or non-peer reviewed websites and blogs. The categories we coded were (1) academic (book or journal), (2) news, (3) government, and (4) other (wikis, blogs and other sources not known to be subject to professional, reliable editorial or peer oversight).

A third test we performed was an analysis of information literacy in the quality of the papers themselves. We used the Information Literacy in Student Writing Rubric developed by the Gould Library Reference and Instruction Department at Carleton College, with possible scores of 3-12, used to assess the papers. Combining dimensions of Implementation of Attribution, Evaluation of Sources, and Communication of Evidence, papers were scored from 1 to 4, with one being "very poor," two being "interferes with goals," three being "does not 
interfere with goals," and four being "very strong." These different categories address some specific questions about the way students use information. Specifically, it provides a guideline for determining whether students select information that contributes to the analytical claims they are making and were they able to use the information they found in a way that supported those claims. This rubric evaluates not just whether students cited a source correctly according to formatting conventions, but whether they selected appropriate sources and used them effectively to build an analytical argument (a complete copy of the rubric is included as Appendix A).

\section{Results}

The results of the paper analyses are divided into four broad tests: (1) source counts, (2) source quality, (3) information literacy, and (4) a correlation between information literacy scores and the paper grades.

In terms of the quantity of sources, a frequency count of sources ranged from papers using as few as two sources and as many as fifteen. The overall mean number of sources in the dataset is 6.23 . The mean number of sources in the absence of a librarian was calculated and compared to the mean number of sources in the presence of an embedded librarian, yielding a mean of 5.432 in 2013 and 7.241 in 2014 (see Table 1). Performing a two-sample t-test comparison of means for the number of sources used in each of the two groups, the results are a $t$ value of -2.938 , significant at a .005 level. 
Table 1. Mean Number of Sources Used, 2013 vs. 2014

\begin{tabular}{|c|c|c|c|c|}
\hline Year & N & Mean & Std.Deviation & Std. Error Mean \\
\hline 2013 & 37 & 5.432 & 2.2053 & .3625 \\
\hline 2014 & 29 & 7.241 & 2.7987 & .5197 \\
\hline
\end{tabular}

To show graphically the association between the presence of an embedded librarian and the number of sources used in student research papers, we recoded the SOURCE variable into one in which those falling at or below the median (6.0) and below the mean (6.227) were coded 0 for "few sources" and those above the mean and median (namely 7-15) were coded 1 for "many sources." The $\mathrm{N}$ for each recoded category was 39 for "few" and 27 for "many," and 55\% of 2014 papers had seven or more source, compared to less than 30\% of 2013 sources (chi-square of 4.354 significant at the .037 level). As depicted in Figure 1 below, there is a striking change in the presence of sources that suggest an improvement under the presence of an embedded librarian.

The second test for the papers pertained to source quality. Each author coded the papers individually, and all scores were reported and recorded. Chiefly, we were interested in the presence of academic sources and non-authoritative online sources such as Wikipedia, blogs, and clearly biased, informal sites (such as the news aggregator site, "I Love Chile!"). Regarding the latter, we found that both classes largely avoid such sources, which is heartening (showing up in only twelve of the 66 papers: eight in 2013, four in 2014; or, a mean of .243 in 2013 compared to .138 in 2014). We also found little difference (and no statistical significance) in the presence of news sources (2013 mean of 1.405 and 2014 mean of 1.621) and government sources (2013 
Figure 1. Number of Sources Used, 2013 vs. 2014

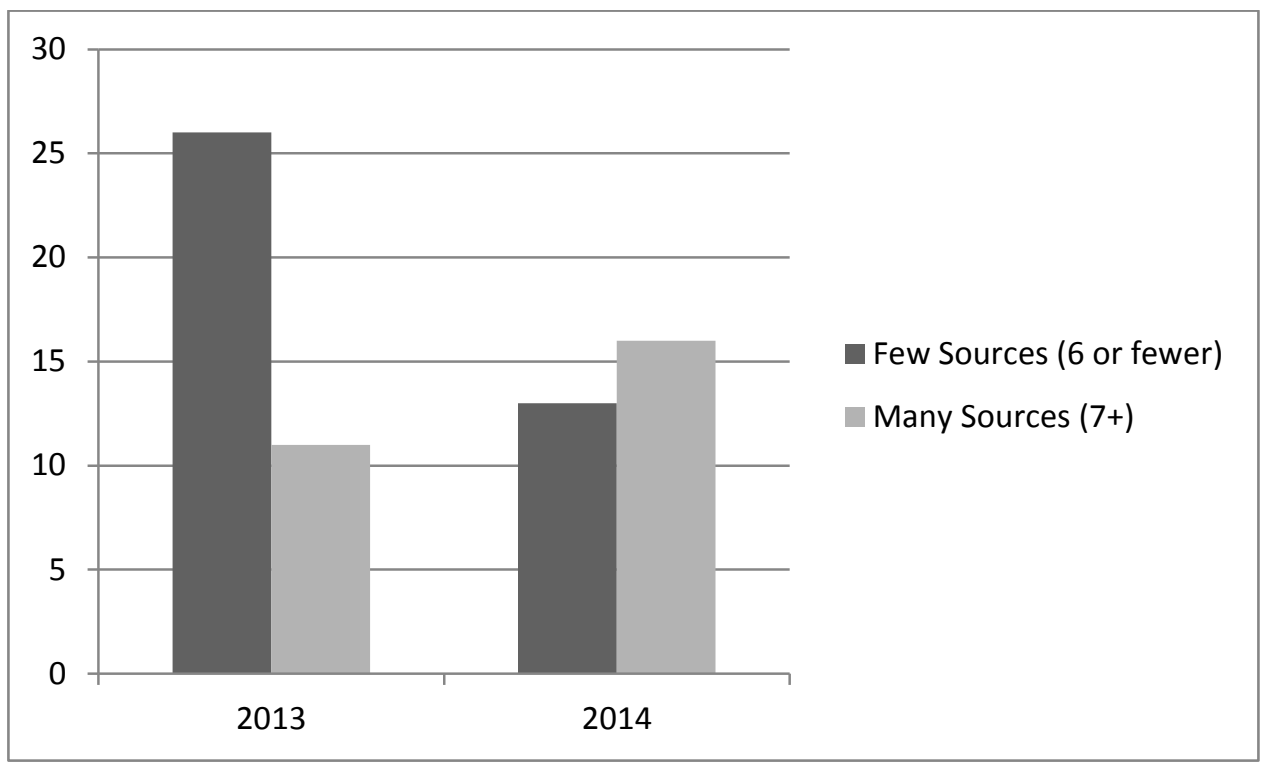

mean of 2.486 versus 2014 2.172). However, we found an important increase in the presence of academic sources with an embedded librarian (a mean of 2.069 in 2014) and--conversely and importantly--a surprising absence of academic sources in the absence of an embedded librarian (a mean of .297 in 2013).

For our third test, that of information literacy, each paper was anonymized and intermingled so that the papers were not immediately recognizable as being from one class or the other. Each author individually scored the anonymized papers according to the Gould Library Information Literacy rubric discussed above. We then compared our individual scores, and found that the inter-coder agreement of the authors was over $75 \%$ (50 of 66 , or $75.8 \%$ ). The authors then reconciled the ones on which they varied and report those scores under the variable RECONCILE. The median in all three sets of scores is 6.0 , and the mean varied from a 6.303 (reconciled) to a 6.439 (See Table 2). 
Table 2. Information Literacy scores, by Coder

\begin{tabular}{|c|ccc|}
\hline $\mathrm{N}=66$ & Author 1 Scores & Author 2 Scores & RECONCILED Score \\
\hline Mean & 6.348 & 6.439 & 6.303 \\
Median & 6.000 & 6.000 & 6.000 \\
Mode & 6.0 & $5.0^{\mathrm{a}}$ & 5.0 \\
\hline
\end{tabular}

We recoded RECONCILE into manageable categories for testing, with papers scoring 35 being recoded as 0 (for poor), scores of 6-9 recoded as 1 (for average), and scores of 10-12 recoded as 2 (for good). The new variable (RECODE.RECON) was then tested against the years 2013 and 2014 (chi-square value of 18.874, significant at less than .001). As shown in Table 3 below, $70 \%$ of the 2013 papers received a "poor" or "low" score, and only one $(2.7 \%)$ achieved a "high" score. Conversely, in 2014 only $20 \%$ received the "low" score, and $31 \%$ achieved the "high" score. $48 \%$ of 2014 papers scored in the middle category, compared to only $27 \%$ of 2013. Figure 2 visually reveals the significant variation by year, implying the role of the embedded librarian instruction.

A final test we did was to examine the relationship between our rubric scores for the papers, and the grades given for the papers in class. We were curious whether information literacy correlated with quality papers in other respects, with the caution that the grading criteria are multiple, and thus a paper could receive a high grade despite low rubric scores or a low grade despite a high rubric score. With our recoded ordinal-level RECONCILE variable, whereby a rubric score of a 3,4 , or 5 is a 0 (poor), and $6,7,8$ or 9 is a 1 (average), and 10,11 , or 12 is a 2 
Table 3. Information Literacy, 2013 vs. 2014

\begin{tabular}{|l|l|l|l|}
\hline & 2013 & 2014 & Total \\
\hline Poor & $26(70.3 \%)$ & $6(20.7 \%)$ & $32(48.5 \%)$ \\
\hline Average & $10(27.0 \%)$ & $14(48.3 \%)$ & $24(36.4 \%)$ \\
\hline Good & $1(2.7 \%)$ & $9(31.0 \%)$ & $10(15.2 \%)$ \\
\hline Total & 37 & 29 & 66 \\
\hline
\end{tabular}

Figure 2. Information Literacy Scores, 2013 vs. 2014

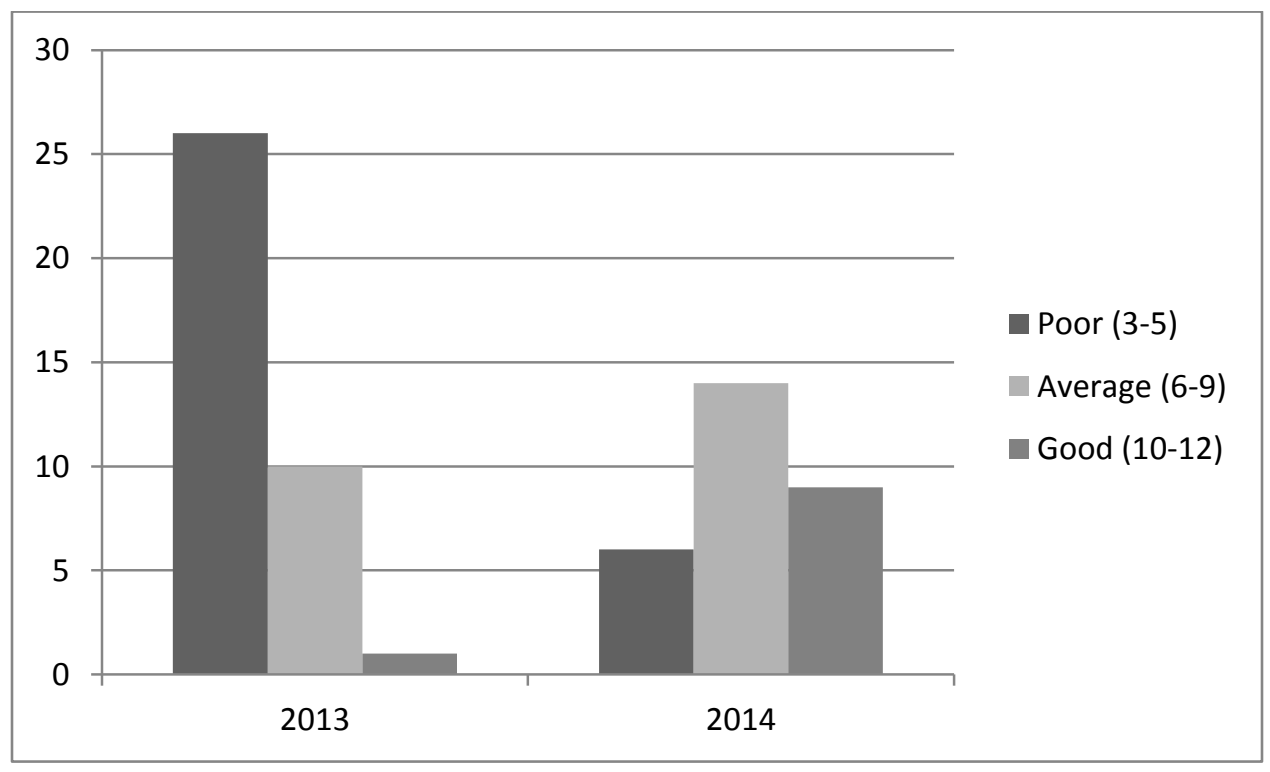


(good), we ran a 2-tailed bivariate correlation against the ordinal-level variable PAPERGRADE, in which A papers were coded a five, B papers coded a four, and $\mathrm{C}$ papers coded a three. ${ }^{3}$ Testing the rubric scores (RECONCILE) for association with grades, we find a positive association of .388 (Spearman's rho, significant at the .001 level). ${ }^{4}$

\section{Implications and Conclusions}

Our tests of association are strongly suggestive of an important role of the librarian in the classroom. Specifically, repeated visits stressing information literacy may significantly affect the number of sources used, the quality of sources used, and the overall quality of the papers students write and professors read. It is important to note that in the collaboration on assignment development and in library instruction, there were no changes in explicit requirements about the quantity or quality of citations that were required. Indeed, no requirements were established on either count. So the results we see are without demanding minimum sources or minimum "academic" sources, making the changes even more remarkable. While some suggest that instruction alone cannot change the quantity or quality of sources used without explicit minimum guidelines for number and type of sources (Robinson and Schlegl 2004), we found the opposite to be true. Both the quantity and quality of student sources improved with library instruction, as did the use of those sources. Considering the varied information needs in a research paper and the vast amount of information available, it is not surprising that students often turn to the

\footnotetext{
${ }^{3}$ There were no D's or F's in the two sets of papers, which would have been coded 1 or 0 respectively.

${ }^{4}$ We ran the GRADE variable against both authors' initial rubric scores for transparency, and found little appreciable difference: a .334 (significant at the .006 level) for author 1, and a .378 (significant at the .002 level) for author 2 .
} 
workaround methods of finding information they have developed using general internet searches (Head 2008). They often don't know what else is available or where to look for it. Through collaboration, the political science faculty and the librarian are able to help students better understand the process of conducting analytical, political science research.

We are aware that the correlations we found between library instruction and student performance has limitations. Specifically, the sample size was small and we cannot eliminate the possibility of spuriousness related to the natural abilities of the students. Despite choosing the same introductory class in the same time of a school year cycle in an attempt to achieve a measure of control and comparability, the individual makeup of the classes remain beyond our control, and could affect the results in this study. Given that information literacy skills would be expected to improve over the course of student academic careers, we examined the two classes for prior experience, based on measures of class rank and prior instruction from a librarian. With respect to class rank, the 2013 and 2014 classes each had eight underclass (freshmen and sophomores), and comparable numbers of upper-class (juniors and seniors): $69.8 \%$ and $66.7 \%$ respectively. The 2014 class had more seniors (16 versus 10) but also more freshmen (three versus zero). In a pretest of student information literacy skills and experience, we asked students, "In any of your prior classes at this university, has a library talked with your class about library skills?" to account for the effects of prior information literacy instruction. There was a noticeable difference, but in a direction that helps, not hurts, our argument: 64\% of the 2013 class answered that they did have prior librarian experience, compared to 50\% of the 2014 class. The fact that 2014 scores were higher despite lower levels of prior library instruction emphasizes that prior experience is not likely to be the primary cause of the students' improved skills. Another area of 
student aptitude we did not address was prior GPA, standardized test scores, and other predictors of student success. Future studies would benefit from collaboration with offices of institutional research to explore this relationship.

Further studies can replicate and expand on these findings beyond one university setting and subject area. But we are encouraged that both professor and student can have a better classroom experience by integrating the library's assets into the classroom in a conscious, deliberate, and routine manner.

Practically, the ability to facilitate embedded librarianship depends on the willingness and availability of both instructor and librarian. The demands of time are great on both, making the idea of multiple, sustained interactions with classrooms challenging. If time and resources are limited, we recommend collaboration between an academic department and the library to determine when in the course sequence library embeddedness would have the greatest impact. In some cases, this would suggest practicing embeddedness early, in introductory courses, when students would begin to understand their information needs in context and be introduced to the variety of sources and resources available for their use. In this case, the lessons of early information literacy would hopefully transfer and endure throughout future political science courses. However, in some cases, the greatest benefit from embeddedness might come from more advanced classes when students have developed foundational knowledge of the discipline and have begun to integrate their research practices into their existing knowledge. The point in the curriculum at which an embedded librarian is likely to have the greatest impact is a question that merits further investigation and research. 
We hope this paper facilitates mutual awareness between instructors and librarians, and fosters dialogue in improving relationships across campus. Students may benefit from improved skills, grades, and overall sense of pride and accomplishment. The instructors may benefit from higher quality projects coming across their desks, and from a better understanding of their students' potential and their library's purpose. The future academic experience should do more than bring students to the library; it should bring the library to the students. 


\section{References}

Association of College and Research Libraries (ACRL). Information Literacy for Faculty and Administrators. Retrieved from http://www.ala.org/acrl/issues/infolit/overview/faculty/faculty.

Barria, Lilian, Melinda Mueller, and Richard Wandling. “Assessment in Action: The Evolution of an Undergraduate Qualitative Research Methods Course.” Paper presented at the annual meeting of the APSA Teaching and Learning Conference, Long Beach, CA, February 8-10, 2013. Available at SSRN: http://ssrn.com/abstract=2210590 or http://dx.doi.org/10.2139/ssrn.2210590

Booth, Char, M. Sara Lowe, Natalie Tagge, and Sean Stone. "Degrees of Impact: Analyzing the Effects of Progressive Librarian Course Collaborations on Student Performance. College and Research Libraries 76 (2015): 623-651.

Choinski, Elizabeth, and Michelle Emanuel. "The One-Minute Paper and the One-Hour Class: Outcomes Assessment for One-Shot Library Instruction.” Reference Services Review 34 (2006): 148-155.

Conway, Aislinn. “One-Shot Library Instruction Sessions May Not Increase Student Use of Academic Journals or Diversity of Sources." Evidence Based Library and Information Practice 10 (2015): 238-240.

Coulter, Priscilla, Susan Clarke, and Carol Scamman. "Course Grade as a Measure of the Effectiveness of One-Shot Information Literacy Instruction.” Public Services Quarterly 3 (2010): 147-163. 
CREDO. Survey of Students and Faculty: Findings, 2015. Retrieved from http://marketing.credoreference.com/acton/attachment/5363/f-00b7/1/-/-/-//Credo\%20Survey\%200f\%20Students\%20and\%20Faculty\%3A\%20Findings.pdf

Edwards, Mary, Swapna Kumar, and Marilyn Ochoa. “Assessing the Value of Embedded Librarians in an Online Graduate Educational Technology Course.” Public Services Quarterly 6 (2010): 271-291.

Evans, Malcolm. "Fast Change: How to Avoid Getting in the Way of Your Own Success." Industrial and Commercial Training 39 (2007): 208-213.

Foster, Stephen. “Information Literacy: Some Misgivings.” American Libraries 4 (1993): 344346.

Gandhi, Smiti. "Faculty-Librarian Collaboration to Test the Effectiveness of a Five-Session Library Instruction Model." Community and Junior College Libraries 12 (2004): 15-48.

Gilbert, Julie, Katherine Knutson, and Christopher Gilbert. “Adding an Integrated Library Component to an Undergraduate Research Methods Course." PS: Political Science and Politics 45 (2012): 112-118.

Gould Library Reference and Instruction Department. "Information Literacy in Student Writing Rubric and Codebook." Northfield, MN: Carleton College, 2012. Retrieved from http://go.carleton.edu/6a

Head, Alison. "Information Literacy from the Trenches: How do Humanities and Social Science Majors Conduct Academic Research?" College and Research Libraries 69 (2008): 427445. 
Head, Alison. "Learning the Ropes: How Freshman Conduct Course Research Once They Enter College," 2013. Retrieved from http://projectinfolit.org/images/pdfs/pil_2013_freshmenstudy_fullreport.pdf.

Hearn, Michael. "Embedding a Librarian in the Classroom: An Intensive Information Literacy Model. Reference Services Review 33 (2005): 219 -227.

Howard, Kristina, Thomas Nicholas, Tish Hayes, and Christopher W. Appelt. "Evaluating OneShot Library Sessions: Impact on the Quality and Diversity of Student Source Use.” Community and Junior College Libraries 20 (2014): 27-38.

Ishiyama, John. "The Structure of an Undergraduate Major and Student Learning: A CrossInstitutional Study of Political Science Programs at Thirty-two Colleges and Universities." Social Science Journal 42 (2005): 359-366.

Ishiyama, John, Marijke Breuning, and Linda Lopez. “A Century of Continuity and (Little) Change in the Undergraduate Political Science Curriculum.” American Political Science Review 100 (2006): 659-665.

Jackson, Brian, Margy MacMillan, and Michelle Sinotte. “Great Expectations: Results from a Faculty Survey of Students' Information Literacy Proficiency.” IATUL Annual Conference Proceedings 35 (2014): 1-23.

Johnson, Marilyn. This Book is Overdue!: How Librarians and Cybrarians can Save us All. New York: Harper, 2010.

Lundstrom, Kacy and Flora Shrode. "Undergraduates and Topic Selection: A Librarian's Role.” Journal of Library Innovation 4 (2013): 23-41.

Marfleet, B. Gregory, and Brian Dille. Information Literacy and the Undergraduate Research Methods Curriculum. Journal of Political Science Education 1 (2005): 175-190. 
McPherson, Ian. "Reflexive Learning: Stages Towards Wisdom with Dreyfus." Educational Philosophy and Theory 37 (2005): 705-718.

National Commission on Library and Information Science. National Program for Library and Information Services. The Information Service Environment Relationships and Priorities. Related Paper No. 5 by Paul G. Zurkowski. NCLIS-NPLIS-5. Washington, DC (1974)

Norelli, Barbara, Kathy Fountain, Lorena O’English, John Hernandez, Rebecca Ohm, Chris Palazzo, Bruce Pencek, and Connie Stoner. "Political Science Research Competency Guidelines", 2008. Retrieved from http://www.ala.org/acrl/aboutacrl/directoryofleadership/sections/lpss/lpsswebsite/publicat ions/publications

Owens, Major R. "The State Government \& Libraries." LJ: Library Journal 101 (1976): 19-28.

"Patrick Ness Slams Library Cuts." The Guardian, July 23, 2011. Retrieved from http://www.theguardian.com/childrens-books-site/2011/jun/23/patrick-ness-carnegieprize-libraries.

Portmann, Chris, and Adrienne Roush. "Assessing the Effects of Library Instruction.” The Journal of Academic Librarianship 30 (2004): 461-465.

Purcell, Kristen, Lee Rainie, Alan Heaps, Judy Buchanan, Linda Friedrich, Amanda Jacklin, Clara Chen, and Kathryn Zickhur. "How Teens do Research in the Digital World," 2012. Retrieved from http://www.pewinternet.org/files/oldmedia//Files/Reports/2012/PIP_TeacherSurveyReportWithMethodology110112.pdf 
Robins, Andrew and Karen Schlegl. "Student Bibliographies Improve When Professors Provide Enforceable Guidelines for Citations." portal: Libraries and the Academy 4 (2004): 275290.

Schulte, Stephanie. "Embedded Librarianship: A Review of the Literature." Evidence Based Library and Information Practice 7 (2012): 122-138.

Soria, Krista, Jan Fransen, and Shane Nackerud. "Library Use and Undergraduate Student Outcomes: New Evidence for Students' Retention and Academic Success." portal: Libraries and the Academy 13 (2013): 147-164.

Stevens, Christy, and Patricia Campbell. "Collaborating with Librarians to Develop Lower Division Political Science Students' Information Literacy Competencies.” Journal of Political Science Education 4 (2008): 225-252.

Tewell, Eamon. "A Decade of Critical Information Literacy." Communications in Information Literacy 9 (2015): 24-43.

Thornton, Stephen. "Information Literacy and the Teaching of Politics." LATISS: Learning and Teaching in the Social Sciences 3 (2006): 29-45.

Thornton, Stephen. "Pedagogy, Politics and Information Literacy." Politics 28 (2008): 50-56. Thornton, Stephen. “From 'Scuba Diving' to 'Jet Skiing'? Information Behavior, Political Science, and the Google Generation.” Journal of Political Science Education 6 (2010): 353-368.

Thornton, Stephen. "Promoting Information Literacy and Information Research." In Handbook on Teaching and Learning in Political Science and International Relations, edited by John Ishiyama, W.J. Miller, and E. Simon, 121-131. Northampton, MA: Edward Elgar, 2015. 
Wahlke, John. "Liberal Learning and the Political Science Major: A Report to the Profession." PS: Political Science and Politics 24 (1991): 48-60.

Walker, Kevin W., and Michael Pearce. "Student Engagement in One-Shot Library Instruction." Journal of Academic Librarianship 40 (2014): 281-290.

Weeks, Linton. “The Old-Fangled Search Engine: In a Digital Age, Do Libraries Still Count? The Washington Post, January 13, 2001, p. C1.

Whitworth, Andrew. Information Obesity. Oxford: Chandos, 2009.

Williams, Michelle, and Jocelyn Evans. "Factors in Information Literacy." Journal of Political Science Education 4 (2008): 116-130. 